\section{Fungsi Sapaan Anda pada Acara Little VIP di Metro TV}

Kity Karenisa

Mahasiswa Pascasarjana Prodi Linguistik UGM

Surel: kitykarenisa@gmail.com

\title{
INTISARI
}

\begin{abstract}
Sapaan Anda yang umumnya digunakan oleh orang dewasa untuk menyapa sesama orang dewasa ternyata digunakan pula untuk menyapa anak-anak. Salah satunya terlihat jelas pada sebuah program wawancara di televisi. Tulisan ini didasari pertanyaan mengapa Anda digunakan secara berbeda pada program televisi dan apakah fungsi yang mendasari penggunaan sapaan tersebut. Walaupun disadari bahwa televisi mencerminkan kenyataan yang terjadi di masyarakat, penelitian ini membatasi kajian dari mencari hubungan langsung serta dari memastikan cerminan kenyataan tersebut dengan penggunaan sapaan Anda pada program wawancara anak-anak di televisi. Data penelitian diambil secara bertujuan dengan sampel tujuh wawancara di acara Little VIP di Metro TV yang dianggap mewakili berbagai kelompok latar belakang anak-anak. Analisis dilakukan melalui dimensi teks sebagaimana yang disampaikan oleh Norman Fairclough dengan memperhatikan unsur representasi (untuk mendapatkan gambaran tentang ideologi yang disampaikan melalui penggunaan sapaan Anda), relasi (untuk mendapatkan gambaran hubung yang ingin dibangun melalui penggunaan sapaan Anda), dan identitas (untuk mendapatkan gambaran identitas penutur dan lawan tutur melalui penggunaan sapaan Anda). Analisis menunjukkan bahwa Anda yang digunakan sebagai sapaan oleh orang dewasa kepada anak-anak tersebut berfungsi untuk mengonstuksi identitas sosial dalam ranah jurnalistik dan mengontruksi identitas sosial yang egaliter antara orang dewasa dan anak-anak.
\end{abstract}

Kata Kunci: sapaan; Anda; anak-anak; televisi; Fairclough

\section{PENGANTAR}

Bahasa Indonesia merupakan bahasa dengan banyak pilihan dalam sapaan. Jika dilihat dalam pilihan paling terbatas, penutur bahasa Indonesia masih harus memilih antara kamu dan Anda sebagaimana yang dikatakan Braun ( 1988: 3 I) bahwa penutur bahasa masih harus memilih T/V. Berkaitan dengan hal tersebut, berdasarkan penelitian yang telah dilakukan terhadap sapaan kamu dan Anda, kamu dianggap sebagai $\mathrm{T}$, yaitu pronomina umum, dan Anda dianggap sebagai $\mathrm{V}$, yaitu pronomina yang dianggap sebagai sapaan yang sopan dan formal. Atau, dalam bahasa yang mempunyai banyak pronomina yang digunakan sebagai sapaan, pronomina satu dianggap sebagai sapaan intim, sedangkan pronomina lainnya dianggap sebagai sapaan sopan. Pembagian peran pronomina inilah yang diambil kamu dan Anda.

Fakta kebahasaan yang terdokumentasi oleh Purwo (I982), Kridalaksana (1982), Alieva (I99I), Wijana (I99I), dan Alwi, dkk. (1998) menunjukkan bahwa dalam bahasa Indonesia, pronomina persona kedua Anda digunakan sebagai sapaan dalam hubungan yang tidak pribadi dan dalam keadaan si penutur tidak ingin bersikap terlalu formal dan terlalu akrab. Anda dianggap sebagai sebutan ketakziman untuk persona kedua serta merupakan panggilan yang sopan dan resmi. Dalam hubungan antarpenutur yang dekat atau penutur lebih tua daripada mitra tutur, digunakan sapaan kamu, bukan Anda.

Belakangan ini terjadi pergeseran dalam penggunaan sapaan Anda. Pada program televisi yang menyajikan wawancara antara orang dewasa (orang tua) dan anak-anak, seperti Little VIP di Metro TV, orang dewasa menyapa anak-anak dengan sapaan Anda. Metro TV sebagai salah satu stasiun televisi swasta di Indonesia memperkenalkan program atau acara Little VIP itu dengan "Program yang menghadirkan anak-anak yang memiliki talenta dan kepercayaan diri serta menarik dalam perbincangan". Program tersebut merupakan program perbincangan (talkshow) yang berdurasi satu jam yang ditayangkan setiap Sabtu, pukul 19.30 WIB. Acara yang dipandu oleh Lies Hartono 
atau yang lebih dikenal dengan Cak Lontong, seorang pelawak, ini mulai ditayangkan pada 14 Januari 2017. Little VIP merupakan acara khusus bincang-bincang atau wawancara dengan pembawa acara (PA) orang dewasa dan bintang tamu (BT) anak-anak pertama di Indonesia. Dalam acara tersebut, PA menggunakan sapaan Anda kepada BT-nya, yaitu anak-anak.

Alieva secara khusus menyatakan bahwa Anda dibuat untuk mengisi sebuah tempat kosong dalam sistem serta paling banyak dijumpai dalam bahasa pers (I99|:245). Fairclough (1995: 6, 9) menyatakan bahwa "Text are social spaces in which two fundamental social processes simultanously accur: cognition and representation of the world, and social interaction. A multifuctional view of text is therefore essential. ... In the three-dimentional framework for CDA I referred to earlier (text, discourse practise, sociocultural practice), the analysis of discourse practice involves attention to processes of text production, distribution, and consumtion."

Dikaitkan dengan wacana media (Eriyanto, 200I; Badara, 20I2; Heryatmoko, 20I6), salah satu dari tiga dimensi Fairclough, yaitu dimensi teks, dapat digunakan untuk mengetahui ideasional atau representasi, relasi, dan identitas. (I) Ideasional atau representasi merujuk pada representasi tertentu yang ingin ditampilkan dalam teks, yang umumnya membawa muatan ideologis tertentu. Analisis ini pada dasarnya ingin melihat bagaimana sesuatu ditampilkan dalam teks yang bisa jadi membawa muatan ideologis tertentu serta bagaimana realitas ditandakan dalam bahasa dan bagaimana bahasa itu memunculkan realitas bentukan tertentu. (2) Relasi merujuk pada analisis tentang bagaimana konstruksi hubungan antara wartawan dengan pembaca, seperti apakah teks disampaikan secara informal atau formal, terbuka atau tertutup. Relasi ini juga melihat bagaimana partisipan dalam media berhubungan dan ditampilkan dalam teks. (3) Identitas mengacu pada konstruksi tertentu dari identitas wartawan dan pembaca, serta bagaimana personal dan identitas ini hendak ditampilkan. Dalam hal ini juga dilihat bagaimana wartawan (termasuk di dalamnya pembawa acara televisi) menempatkan dan mengidentifikasi dirinya dengan masalah dan kelompok sosial yang terlibat.

Pada wawancara antarorang dewasa di televisi, kata sapaan Anda memang telah lama digunakan. Tidak demikian halnya dengan kata sapaan Anda yang digunakan kepada anak-anak. Dengan melihat ketidakumuman penggunaan sapaan Anda pada program televisi tersebut, penelitian ini bertujuan untuk memperoleh gambaran yang jelas tentang fungsi sapaan kata Anda kepada anak-anak dengan berusaha untuk menjawab pertanyaan umum "Apa fungsi sapaan Anda pada acara televisi dalam percakapan antara orang dewasa dan anak-anak berdasarkan dimensi teks?" dengan menjawab pertanyaan-pertanyaan khusus: (I) Apa gambaran ideologi yang direpresentasi melalui penggunaan sapaan Anda pada acara Little VIP? (2) Apa gambaran hubungan antarpenutur yang direlasikan melalui penggunaan sapaan Anda pada acara Little VIP? (3) Apa gambaran identitas yang teridentifikasi melalui penggunaan sapaan Anda pada acara Little VIP?

Data yang dianalisis dalam penelitian ini dikumpulkan dengan memilih dari 49 video yang dapat diunduh dari http://video.metrotvnews.com/little-vip. Kriteria pemilihan berdasarkan kategori kelompok mitra tutur dalam acara Little VIP, yaitu umur, daerah asal, dan jumlah mitra tutur. Dasar umur mengambil mitra tutur tertua dan termuda. Dasar daerah asal mengambil mitra tutur yang berasal dari berbagai wilayah di Indonesia. Dasar jumlah mitra tutur mengambil mitra tutur yang berjumlah satu, dua, tiga orang, dan kelompok besar. Analisis data dilakukan dengan menggunakan pendekatan yang dikenalkan oleh Fairclough (1995: 4-10 dan 187--213) dalam menganalisis teks dalam penelitian sosial yang berkaitan dengan unsur (I) representasi, (2) relasi, dan (3) identitas. Dalam melihat ketiga hal tersebut, yang menjadi pusat perhatian adalah setiap tuturan PA yang dalam penelitian ini berposisi sebagai penutur kepada bintang tamu yang berposisi sebagai mitra tutur. Tuturan tersebut adalah tuturan yang mengandung sapaan Anda. Diperhatikan pula respons mitra tutur terhadap sapaan tersebut, kemudian relasi hubungan apa yang terbangun berdasarkan maksud penggunaan sapaan Anda oleh penutur sehingga dapat dianalisis pula hubungan yang tercipta di antara penutur dan mitra tutur dalam acara tersebut. Pemaparan hasil analisis dan pembahasan dilakukan berdasarkan data yang ditranskripsi dari tujuh video yang dianggap mewakili kelompok-kelompok mitra tutur yang dimaksud. 
Capaian tujuan penelitian ini dapat dimanfaatkan untuk pendeskripsian penggunaan sapaan Anda dalam konteks penggunaan termutakhir, terutama akan sangat bermanfaat bagi bukan penutur asli bahasa Indonesia. Penutur asing akan mendapat manfaat maksimal dari penelitian ini karena intuisi dan sensitivitas berbahasanya tidak akan pernah sama dengan penutur asli.

\section{HASIL DAN PEMBAHASAN}

\section{Fungsi Sapaan Anda Berdasarkan Usia Mitra Tutur}

Berdasarkan usia mitra tutur, BT tertua yang diwawancara oleh PA adalah seorang anak bernama Ratnanto Adhiputra Wicaksono yang duduk di kelas 2 SMA dan berumur 16 tahun. Prestasinya adalah kepiawaian dalam mendalang dan memenangkan banyak lomba mendalang dan macapat. Sementara itu, BT termuda berumur 2 tahun bernama Moonela, seorang anak yang terkenal karena mempunyai banyak pengikut di Instagram, sebuah media sosial berbasis foto juga pos video.

Pada awal percakapan, PA menanyakan nama panggilan atau nama kecil BT. Pertanyaan itu ditanggapi oleh bintang tamu dengan menyebutkan nama panggilan (baris 2). Namun, PA tidak menggunakan nama panggilan itu untuk menyapa BT pertama kali dan seterusnya (dimulai baris 4). Hingga akhir percakapan, PA secara konsisten menggunakan sapaan Anda. Hal ini berbeda dengan PP. Dengan mengetahui nama panggilan dan BT adalah orang Jawa, PP menyapa BT dengan sapaan Mas yang diikuti nama panggilan (baris 7).

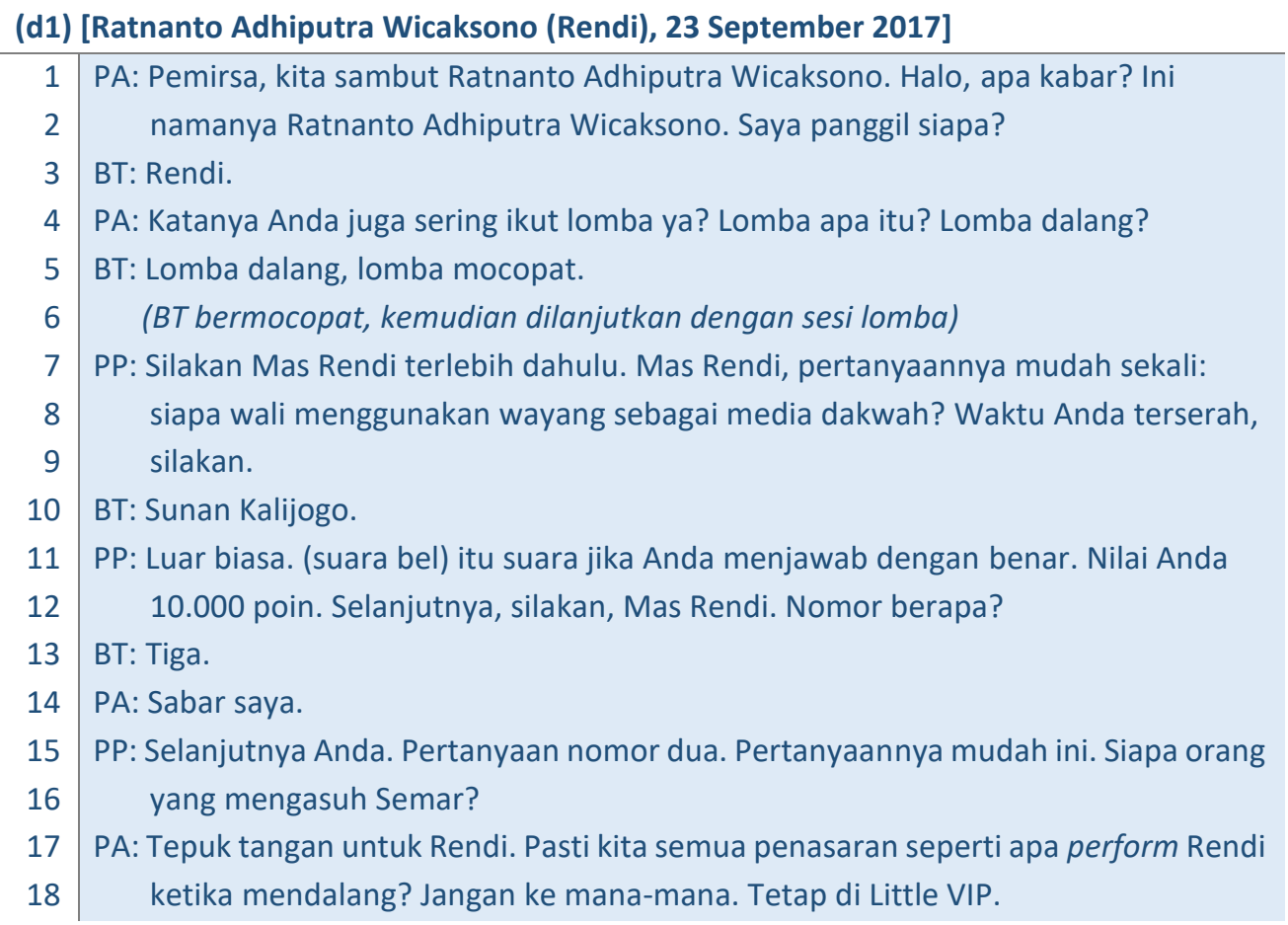

Sementara itu, BT termuda berumur 2 tahun bernama Moonela, seorang anak yang terkenal karena mempunyai banyak pengikut di Instagram, sebuah media sosial berbasis foto juga pos video. Pada awal percakapan, setelah menanyakan nama panggilan dan dijawab dengan "Baby Moonela" oleh BT, PA menyapa BT dengan sapaan Anda (baris 6), tetapi hanya diulangi sekali lagi oleh PA (baris 12). Lawan tutur berumur 2 tahun tersebut telah memahami penggunaan sapaan Anda sehingga ia merespons PA dengan baik (baris 7) walaupun tidak tepat. PA menanyakan kelas dan usia. Untuk kedua pertanyaan itu, BT menjawab dengan jawaban sama, yaitu "dua”. Karena BT yang terlalu muda, PA kesulitan untuk menarik perhatian BT. Salah satu cara yang dilakukannya adalah menyebut dirinya sebagai "uncle" (baris 24) kepada BT. Hal ini diduga menyebabkan PA lebih memilih sapaan dengan nama "Moonel” kepada Baby Moonela. Hingga akhir wawancara, PA lebih memilih menggunakan panggilan Moonel atau Baby Moonela daripada menggunakan sapaan Anda untuk bintang tamu berusia 2 tahun tersebut. 
(d2) [Selebgram Cilik Baby Moonella, 10 April 2017]

1 PA: Tadi ke sini sama mami ya? (ibu Moonela masuk). Boleh. Boleh duduk sama mami. Baby Moonela. Panggilannya siapa?

BT : Baby Moonela.

PA: Panggilannya siapa?

BT: Baby Moonela.

PA: Kelas berapa Anda sekarang?

BT: Du..a.

PA: Kelas dua? Oh luar biasa. Umurnya berapa umurnya?

BT: Dua.

PA: Oh, umurnya dua juga. Pemirsa pasti penasaran ini. Beliau ini sekarang mendapat julukan selebgram cilik. Beliau ini punya follower 520.000. (tayangan tentang Moonela) Anda. Itu pakai admin atau dioperasikan sendiri instagramnya?

BT: Iya.

PA: Monel suka main apa?

BT: Boneka.

PA: Boneka mana yang paling Moonel suka? Moonel suka boneka yang mana? Itu yang boneka kecil itu punya siapa?

BT: Dedek bayi.

PA: Ini siapa namanya?

BT: Titi Priti.

PA: Moonel bisa nyanyi? Katanya pintar nyanyi. Ayo nyanyi yo..

(musik)..ABCD..(Moonela menyanyi)

PA: Hore, tepuk tangan. Aduh pinter banget. Ini..ini boneka ini uncle punya. Moonel cita-citanya mau jadi apa?

BT: Jadi dokter.

PA: Oh dokter.

BT: Dokter dede bayi.

PA: Oh, dokter anak.

BT: Bukan. Dokter Moonel.

PA: Terima kasih, Moonel, Mami Moonel. Kapan-kapan kami undang lagi ke Little VIP mau?

BT: Mau.

PA: Terima kasih, Moonel.

Sebagaimana yang dikatakan oleh Braun (1988) bahwa bahwa nama kecil, istilah kekerabatan, dan pronomina $T$ digunakan dalam ragam intim atau ragam yang menganggap lawan tutur berada di posisi yang lebih rendah. PA dalam percakapannya dengan lawan tutur anak-anak (remaja dan balita) menggunakan sapaan Anda. Ketika menggunakan Anda, sementara kedekatan hubungan belum juga terjalin, PA mencoba mendekatkan diri dengan menggunakan sapaan nama kecil. Dalam hal ini, PA memosisikan dirinya bukan sebagai PA, tetapi sebagai paman (PA menyebut dengan uncle) bagi lawan tutur (d.2 baris 24). Untuk lawan tutur yang hampir meninggalkan usia anak-anak, PA secara konsisten menggunakan sapaan Anda. Untuk lebih intim atau untuk memosisikan lawan tutur lebih rendah, sebenarnya PA mempunyai pilihan untuk menggunakan nama panggilan. Namun, PA sama sekali tidak mengubah bentuk sapaan yang digunakannya. PP menggunakan nama panggilan ketika menyapa $\mathrm{BT}$, tetapi memadukannya dengan $\mathrm{KT}$ atau sapaan dengan istilah kekerabatan mas yang membuat panggilan itu dikategorikan sebagai $\mathrm{V}$, bukan $\mathrm{T}$.

Konteks wawancara di televisi dan penggunaan sapaan Anda oleh PA kepada mitra tutur yang berusia sangat muda dan remaja menunjukkan beberapa hal. Melalui dimensi teks yang konsisten 
dengan penggunaan sapaan Anda, PA merepresentasikan hakikat nilai anak-anak yang tidak berbeda dengan manusia lainnya, yang dalam hal ini adalah orang dewasa. Dalam relasinya, penutur ingin relasi yang menunjukkan keegaliteran dengan mitra tutur. Dalam identitasnya, PA menegaskan bahwa tidak ada perbedaan antara mitra tutur dewasa dan mitra tutur anak-anak dalam dunia jurnalistik. Jika wawancara dengan siapa pun digunakan sapaan Anda (karena BT wawancara pada acara perbincangan di televisi selama ini memang orang dewasa), PA tidak membedakan antara anak-anak dan orang dewasa ketika seseorang menjadi BT-nya dalam sebuah wawancara jurnalistik di televisi.

\section{Fungsi Sapaan Anda Berdasarkan Asal Mitra Tutur}

Sapaan dalam bahasa Indonesia banyak dipengaruhi bahasa ibu dan latar belakang budaya penutur dan mitra tutur. Orang Sumatra lebih biasa dengan sapaan kau/engkau daripada kamu, sebaliknya dengan orang Jawa yang lebih terbiasa dengan sapaan kamu daripada engkau. Baik penutur maupun mitra tutur dipengaruhi latar belakang budayanya.

Ketika mewawancarai BT yang merupakan orang Jawa, orang Kalimantan, dan orang Sumatra Utara, PA yang orang Jawa tetap secara konsisten menggunakan sapaan Anda (d3 baris I, 5, 7, I2, I5, 18, 24, 32, 35, 4I). Tidak ada keraguan bagi PA untuk menggunakan sapaan Anda saat berwawancara dengan Krisna yang mempunyai kemampuan meniru suara binatang dan bendabenda tertentu. Perhatikan kutipan data $\mathrm{d} .3$ berikut.

(d3) [Krisna Peniru Suara, 10 Juni 2017]

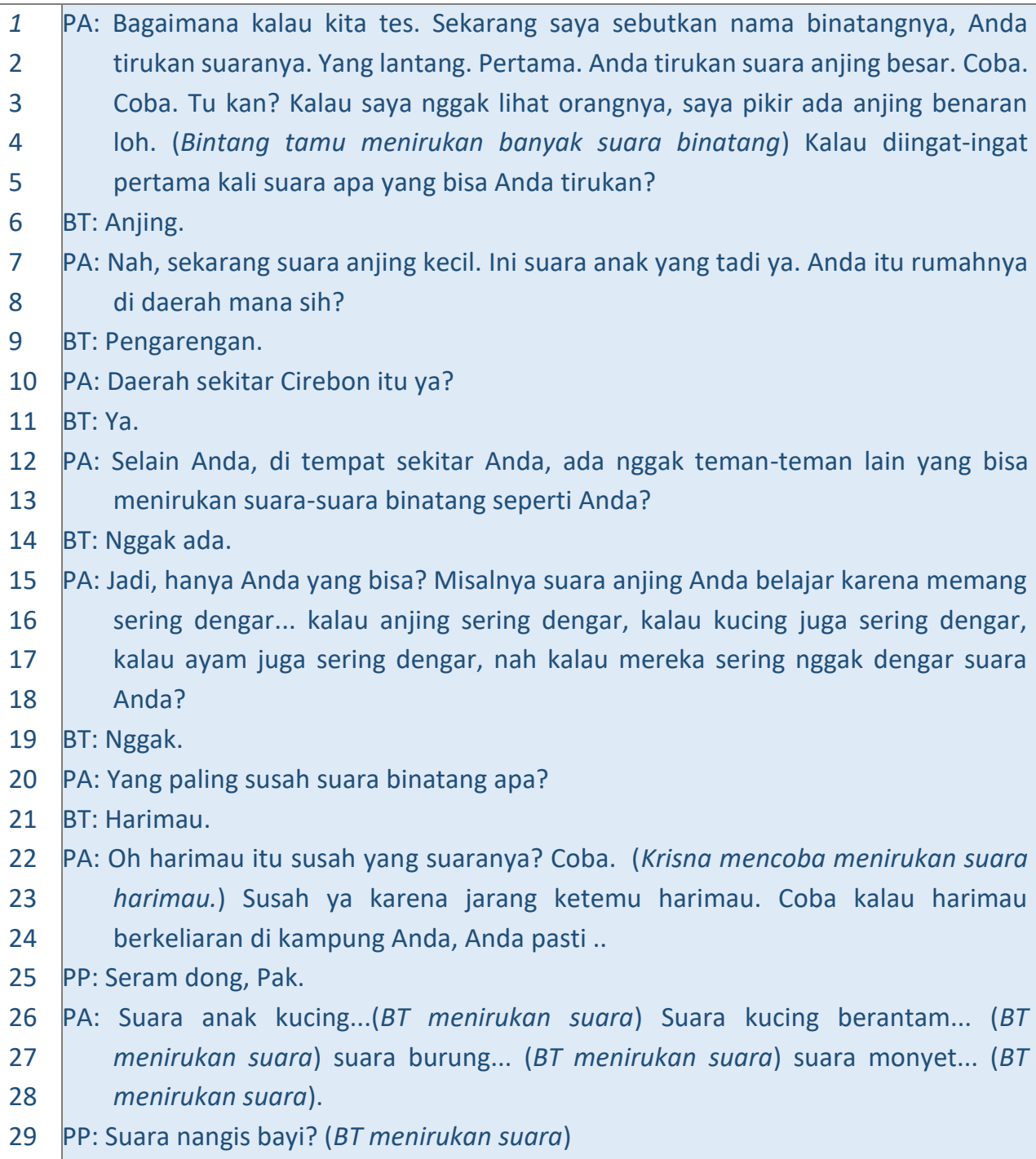




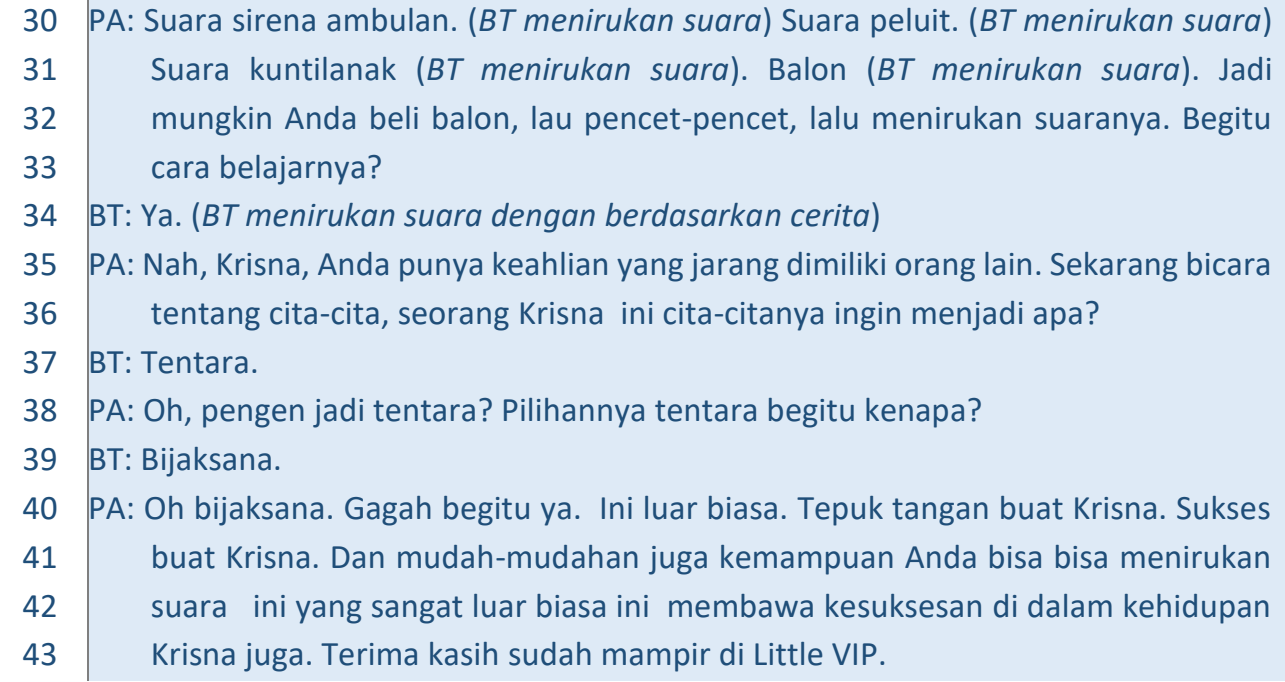

PA melakukan hal yang sama ketika mewawancarai Raqxel Alkadri yang mempunyai prestasi dalam mendongeng. Raqxel yang berasal dari Kalimantan Barat tidak mempengaruhi penggunaan sapaan Anda dari penutur kepada lawan tutur (d4 baris 5, 19, 21, 24). Dalam hal ini, PA menyapa penontonnya dengan Anda sama seperti sapaannya kepada Raqxel yang bernama panggilan Ecel (d4 baris 2).

\section{(d4) [Raqxel Alkadrie, 14 Januari 2017]}

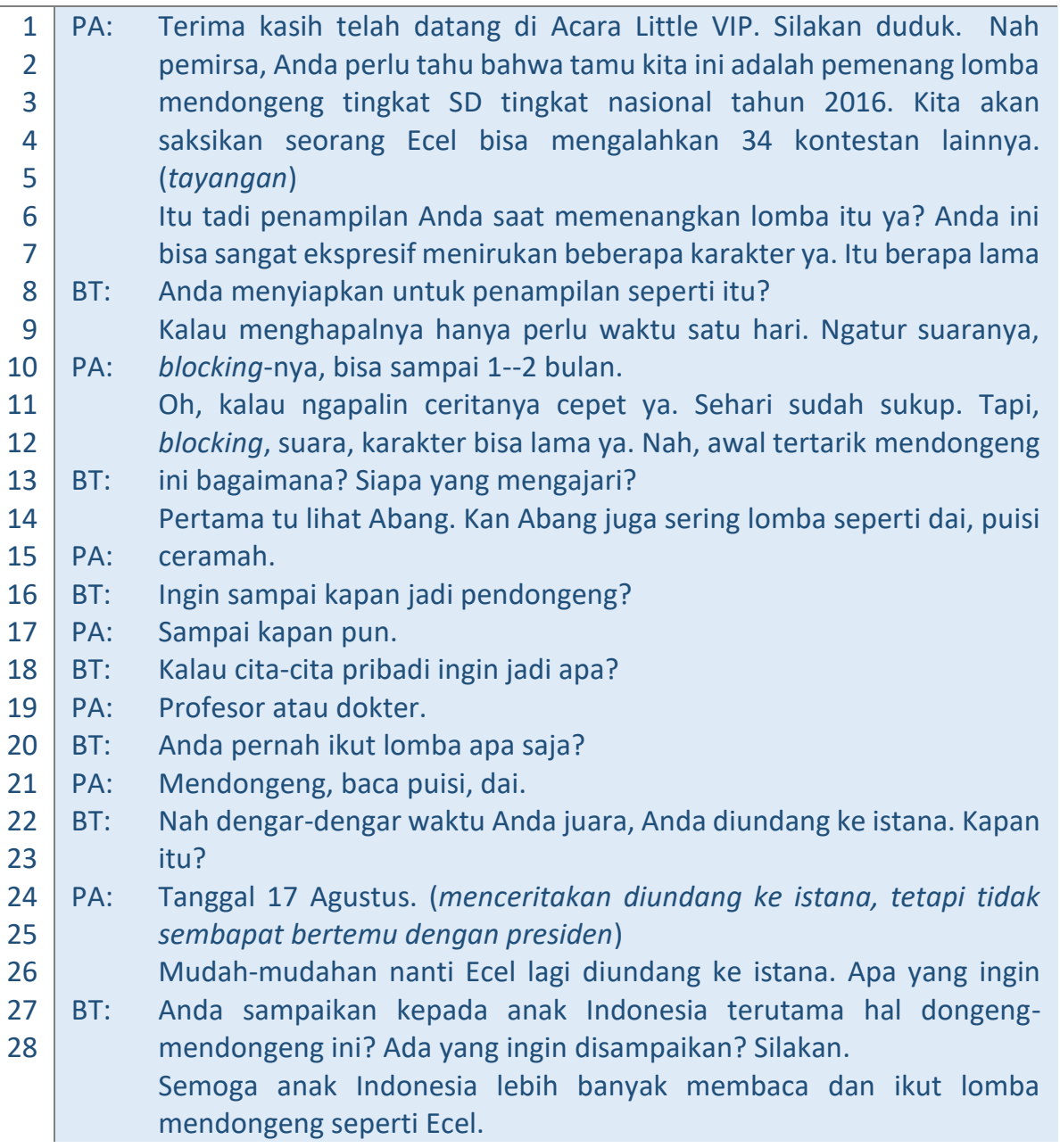


Data 6 (d6) di bawah merupakan percakapan PA dengan BT yang berasal dari Sumatra Utara. Ketiga orang BT tersebut merupakan anak bermarga Batak. Orang Batak yang terbiasa disapa dengan kau itu tetap disapa Anda oleh PA (d6 baris 2, 12, I5, 16, 20, 24).

Berdasarkan daerah asal mitra tutur, ketika mewawancarai BT yang merupakan orang Jawa, orang Kalimantan, dan orang Sumatra Utara, PA yang orang Jawa tetap secara konsisten menggunakan sapaan Anda. Konteks wawancara di televisi dan penggunaan sapaan Anda oleh PA kepada mitra tutur yang berasal dari latar belakang budaya dan bahasa yang berbeda menunjukkan beberapa hal. Melalui dimensi teks yang konsisten dengan penggunaan sapaan Anda, PA merepresentasikan hakikat nilai anak-anak yang tidak berbeda dengan manusia lainnya, yang dalam hal ini entah dari mana pun asalnya. Dalam relasinya, penutur ingin relasi yang menunjukkan keegaliteran dengan mitra tutur, bahwasanya manusia itu sederajat. Jika mitra tutur A dapat disapa dengan Anda, tentu mitra tutur B dapat disapa dengan Anda juga. Dalam identitasnya, PA menegaskan bahwa tidak ada perbedaan antara mitra tutur yang berasal dari Jawa, Sumatra, Kalimantan, dan daerah lainnya.

\section{Fungsi Sapaan Anda Berdasarkan Jumlah Mitra Tutur}

Bahasa Indonesia membedakan antara pronomina orang kedua tunggal dan pronomina orang kedua jamak. Anda atau kamu menunjukkan ketunggalan, sedangkan Anda sekalian dan kamu sekalian (kalian) menunjukkan kejamakan. Namun, dalam penggunaannya sebagai sapaan, Anda pun dapat digunakan untuk menyapa lebih dari satu orang.

Ketika mewawancari satu orang (pada dI, d2, d3, d4), PA menggunakan sapaan Anda. Sapaan yang sama digunakan oleh PA ketika mewawancarai dua orang. Hal ini terlihat pada data (d5) berikut ini. Pada bagian ini PA mewawancarai dua orang anak bernama Rafif Dista Serano dan Axel Geovani Hartanto yang merupakan juara olimpiade sains dan matematika.

(d5) [Rafif dan Exel, Juara Olimpiade, 8 Juli 2017]

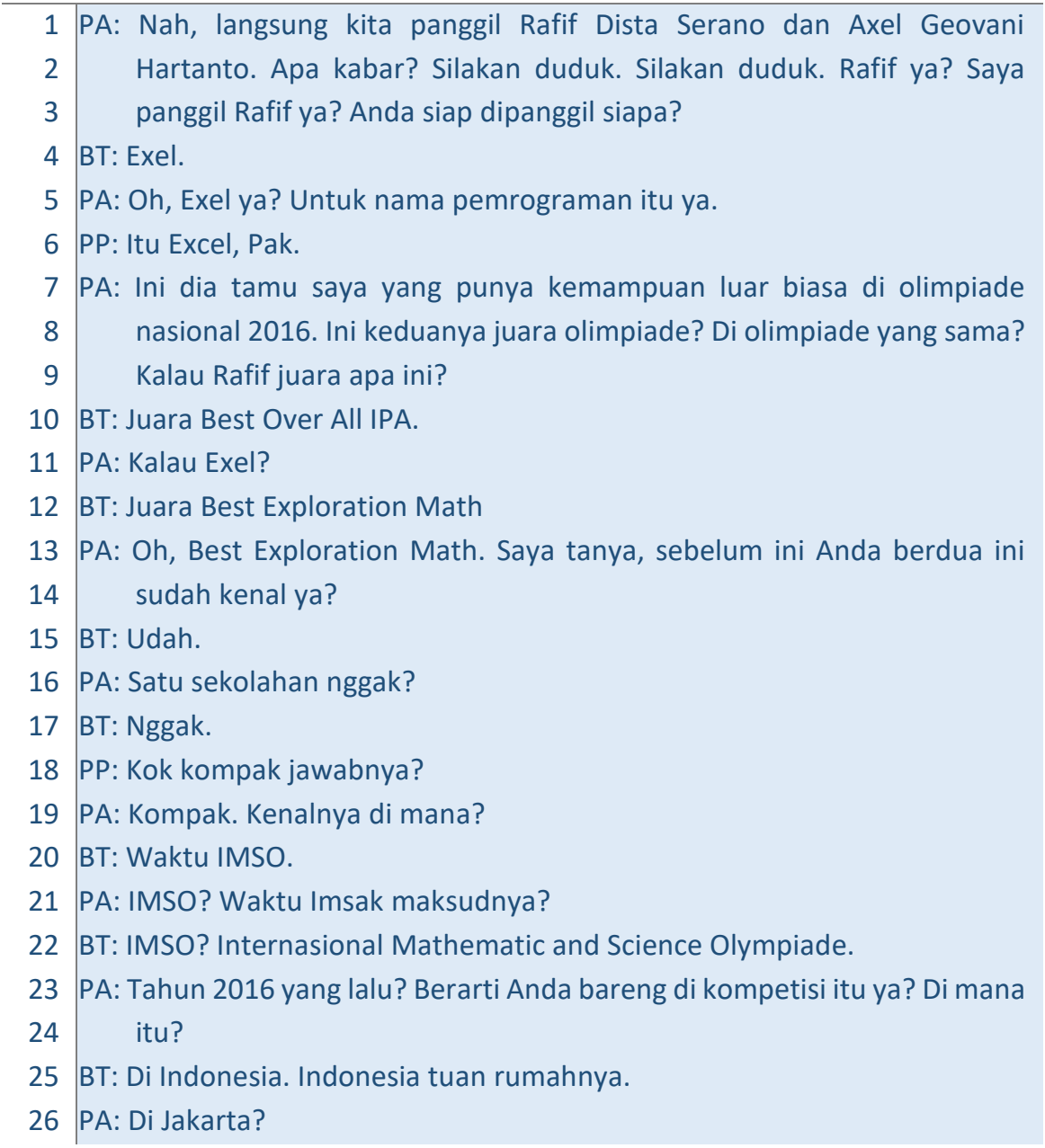


27 BT: Bukan di Tangerang.

28 PA: Anda dikarantina? Berapa lama dikarantina?

29 BT: Biasanya seminggu.

30 PA: Ngapain saja Anda seminggu?

31 BT: Belajar, tidur, main, belajar, tidur, main.

32 PA: Belajar, tidur, main, belajar, tidur, main. Nggak makan?

33 BT: Makan juga.

34 PA: Rata-rata yang menurut Anda nyaman sekali belajar berapa lama?

35 BT: Dua jam.

36 PA: Kalau Exel?

37 BT: Maksimal 4 jam

38 PA: Saya juga begitu. Kalau belajar ya.

39 PP: Ini saya penasaran dengan piala yang ada di situ?

40 PA: Ini punya siapa? Exel? Hati-hati, jangan ditaruh di sini. Saya dengar Anda

41 berdua ini punya kesamaan. Saya dapat info Anda berdua sama-sama

42 suka main games? Benar?

43 PP: Madam sudah melihat kedua piala Anda dan Madam tidak meragukan

44 kemampuan Anda. Tapi, keberatan nggak kalau Anda berdua saya tes?

45 BT: Tidak?

46 PP: Karena Anda berdua akan melawan orang tua.

47 PA: Madam akan menguji kemampuan dua anak muda ini dengan orang tua

(Cak Lontong dan Abdel))

Hal yang membedakan sapaan yang digunakan ketika mewawancarai satu orang dan ketika mewawancarai dua ini adalah perluasan penggunaan sapaan Anda dengan keterangan kelompok jumlah di belakangnya, yaitu Anda berdua (d5 baris 13, 40-4I, 44, 46). Kata berdua pada sapaan tersebut menunjukkan jumlah penutur yang jamak. Selain itu, untuk mengkhususkan pertanyaan pada satu orang, PA mengubah sapaan Anda menjadi nama panggilan. Hal ini dilakukan oleh PA agar tidak ada kebingungan dari kedua BT untuk menjawab pertanyaan yang diajukan (d5 baris 9, II, 36). Namun, pada dasarnya PA tetap menggunakan sapaan Anda sebagaimana ketika digunakan dalam menyapa satu orang (d5 baris $3,28,34,43,44)$.

Ketika mewawancarai Parna Brother, sebuah kelompok vokal anak-anak, PA pun menggunakan sapaan Anda. Namun, berbeda dengan ketika mewawancarai dua orang pada (d5), pada (d6) ini PA hanya menggunakan sapaan Anda. Hal yang sama dengan ketika mewawancarai dua orang pada (d5) adalah bahwa untuk mengkhususkan pertanyaan pada satu orang, PA mengubah sapaan Anda menjadi nama panggilan. Hal ini dilakukan oleh PA agar tidak ada kebingungan dari ketiga BT untuk menjawab pertanyaan yang diajukan ( 6 6 baris II, I2, 23, 25). Namun, pada dasarnya PA tetap menggunakan sapaan Anda sebagaimana ketika digunakan dalam menyapa satu orang ( $\mathrm{d} 6$ baris 2 , I2, I5, 20, 25).

\section{(d6) [Parna Brother, 5 Agustus 2017]}

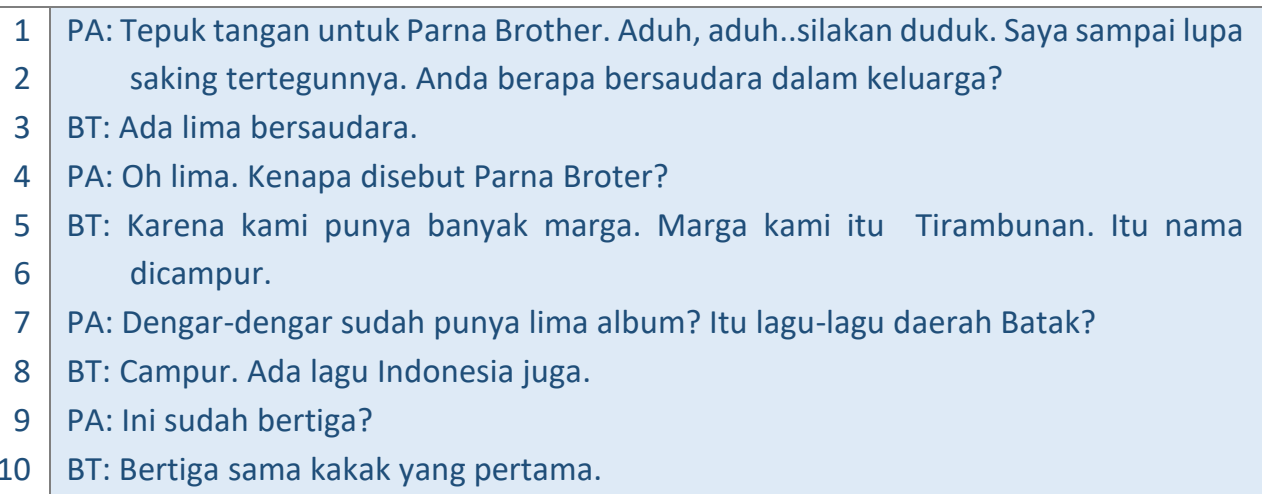


11 PA: Oh James belum bergabung dengan ya? James sudah gabung berapa lama? Kalau

Kelompok kesenian yang berasal dari Lab School Jakarta yang beranggotakan 28 orang diwawancarai. Namun, hanya ada lima anak yang mewakili kelompok kesenian tersebut. Data 7 (d7) memperlihatkan bahwa PA hanya menggunakan bentuk sapaan Anda dalam mewawancarai lima orang tersebut (d7 baris I, 8).

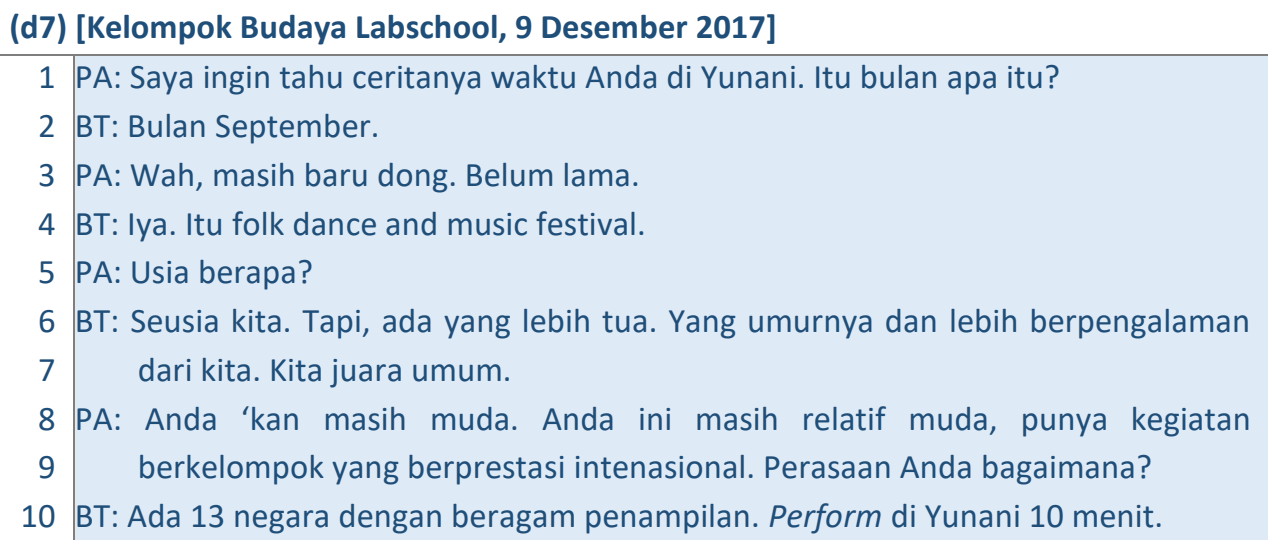

Berdasarkan jumlah mitra tuturnya, ketika mewawancarai satu orang, PA menggunakan sapaan Anda. Sapaan yang sama digunakan oleh PA ketika mewawancarai dua orang dan lebih daripada lima orang meskipun bahasa Indonesia membedakan antara pronomina orang kedua tunggal dan pronomina orang kedua jamak. Anda atau kamu menunjukkan ketunggalan, sedangkan Anda sekalian dan kamu sekalian (kalian) menunjukkan kejamakan. Namun, dalam penggunaannya sebagai sapaan, Anda pun dapat digunakan untuk menyapa lebih dari satu orang.

Konteks wawancara di televisi dan penggunaan sapaan Anda oleh PA kepada mitra tutur yang berjumlah lebih dari satu orang menunjukkan beberapa hal. Melalui dimensi teks yang konsisten dengan penggunaan sapaan Anda, PA merepresentasikan hakikat nilai anak-anak yang tidak berbeda dengan manusia lainnya, yang dalam hal ini adalah orang dewasa. Dalam relasinya, penutur ingin relasi yang menunjukkan keegaliteran dengan mitra tutur. Dalam identitasnya, PA menegaskan bahwa ada perbedaan antara mitra tutur satu orang, dua orang, dan mitra tutur lebih dari dua orang. PA pada dasarnya tidak membedakan antara seorang anak dan banyak anak ketika seseorang menjadi BT-nya dalam sebuah wawancara jurnalistik di televisi. Hal lainnya yang menyebabkan PA lebih banyak menggunakan sapaan Anda daripada Anda berdua adalah adanya satu orang yang selalu menjadi wakil teman-temannya. Oleh karena itulah, PA menggunakan sapaan Anda alih-alih kalian atau Anda sekalian atau Anda berdua. 


\section{Konstruksi Sapaan Anda kepada Mitra Tutur Anak-Anak}

Penggunaan sapaan Anda yang digunakan PA sebagai penutur kepada lawan tutur anak-anak yang berbeda dalam rentang usia, dalam latar belakang daerah asal, dan dalam jumlah lawan tutur menunjukkan penggunaan sapaan Anda yang sangat dominan. Dikatakan sangat dominan karena selain menggunakan sapaan Anda, PA juga menggunakan nama panggilan untuk mengarah pada seorang BT secara khusus.

Berdasarkan pembahasan tersebut, dapat dikatakan bahwa sapaan Anda pada acara Little VIP berfungsi untuk

a. mengonstuksi hakikat manusia, yaitu bahwa tidak ada perbedaan antara anak-anak dan orang dewasa dalam kemampuan untuk berprestasi; anak-anak mempunyai nilai yang sama dengan orang dewasa dalam hakikatnya sebagai manusia;

b. mengonstuksi relasi sosial yang egaliter antara orang dewasa dan anak-anak;

c. mengonstuksi identitas sosial, yaitu bahwa anak-anak (sebagai subjek wawancara/ bintang tamu) sama dengan orang dewasa dalam perlakuan di ranah jurnalistik.

\section{KESIMPULAN}

Konteks sosial maupun kebahasaan diperkirakan menjadi dasar mulai digunakannya sapaan Anda kepada anak-anak. Penggunaan Anda untuk menyapa anak-anak dalam sebuah program terlevisi mulai menujukkan bahwa dalam wawancara di televisi, sapaan Anda digunakan tanpa pengecualian. Artinya, sapaan Anda tidak membedakan orang yang diwawancarai berdasarkan latar belakangnya, termasuk usianya. Oleh karena itu, anak-anak disapa menggunakan kata sapaan yang sama ketika mewawancarai orang dewasa.

Dalam konteks kebahasaan, wawancara di televisi dan penggunaan sapaan Anda oleh PA kepada mitra tutur yang berasal dari latar belakang budaya dan bahasa yang berbeda menunjukkan beberapa hal. Melalui dimensi teks yang konsisten dengan penggunaan sapaan Anda, PA merepresentasikan hakikat nilai anak-anak yang tidak berbeda dengan manusia lainnya, yang dalam hal ini entah umut, dari mana pun asalnya, serta latar belakangnya. Dalam relasinya, penutur ingin relasi yang menunjukkan keegaliteran dengan mitra tutur, bahwasanya manusia itu sederajat. Jika mitra tutur A dapat disapa dengan Anda, tentu mitra tutur B dapat disapa dengan Anda juga. Dalam identitasnya, PA menegaskan bahwa tidak ada perbedaan antara mitra tutur yang berasal dari Jawa, Sumatra, Kalimantan, dan daerah lainnya.

\section{DAFTAR PUSTAKA}

Alieva, N.F., dkk. 199I. Bahasa Indonesia: Deskripsi dan Teori. Yogyakarta: Kanisius.

Badara, Aris. 2012. Analisis Wacana: Teori, Metode, dan Penerapannya pada Wacana Media. Jakarta: Kencana.

Braun, Frederica. 1988. Terms of Address: Problems of Patterns and Usage in Various Languages and Cultures. Berlin: Mouton de Gruyter.

Eriyanto. 200I. Analisis Wacana: Pengantar Analisis Teks Media. Yogyakarta: LKiS.

Fairclough, Norman. 1995. Critical Discourse Analysis: The Critical Study of Language. London: Longman.

Heryatmoko. 2016. Critical Discourse Analysis (Analisis Wacana Kritis): Landasan Teori, Metodologi, dan Penerapan. Depok: RajaGrafindo Persada.

Kaswanti Purwo, Bambang. 1982. Deiksis dalam Bahasa Indonesia. Jakarta: Balai Pustaka.

Kridalakasana, Harimurti. 1982. "Dinamika Tutur Sapa dalam Bahasa Indonesia" dalam Purwo, Bambang Kaswanti. Pelangai Bahasa: Esai Persembahan kepada Prof. Dr. J.W.M. Verhaar, S.J. Jakarta: Bhrata Karya Aksara.

Wijana, I Dewa Putu. 199I. "The Use of Term of Address in Bahasa Indonesia" laporan penelitian pada Fakultas Sastra Universitas Gadjah Mada Yogyakarta. 